\title{
REKONSTRUKSI PENDIDIKAN ISLAM DALAM PERSPEKTIF MUHAMMAD ABDUH
}

\author{
Muhammad Jamaluddin'; Moh. Laili'; ${ }^{2}$ Moh. Zaiful Rosyid ${ }^{3}$ \\ Institut Agama Islam Negeri Madura \\ 1]amal_aldien@yahoo.co.id \\ 2moh.laily111@gmail.com \\ 3zaifulrosyid@gmail.com
}

\begin{abstract}
Education is a major milestone in advancing a nation, with a good nation's education will make a nation that is developed, peaceful and prosperous. Muhammad Abduh planned that there would be a concrete change in education at that time, he had an important role in an al-Azhar tertiary education. Muhammad Abduh slowly entered the education curriculum starting from the basic, secondary, upper and tertiary level curriculum, as well as the philosophy of education in the existing courses at al-Azhar higher education, not only stopped in the curriculum, Muhammad Abduh also made improvements to the methods learning method, because at that time the method applied was only focused on writing and memorizing, so according to Muhammad Abduh it was very difficult for students to progress and develop, so with that all Muhammad Abduh gave a new method, namely Discussion. Because the discussion learning method of a student will increase his scientific insight.
\end{abstract}

Keywords: Education, Curriculum, Methods

\section{Pendahuluan}

Salah satu isu penting yang menjadi sorotan Muhammad Abduh dalam kehidupannya dan karirnya adalah pembaharu pendidikan, baginya Pendidikan merupakan tonggak utama dalam memajukan suatu bangsa, dengan pendidikan bangsa yang bagus akan menjadikan bangsa yang maju, sentosa dan makmur. Sedangkan ilmu pengetahuan itu wajib dipelajari. Yang menjadi perhatiannya adalah mencari alternative untuk keluar dari stagnasi yang dihadapinya sendiri dari sekolah agama mesir (Suwito, 2005: 88). Maka dengan hal tersebut pendidikan mempunyai peran yang urgen dalam sebuah kebangkitan suatu bangsa, tidak jauh beda dengan apa yang dilkaukan oleh pembaharu pemikiran pendidikan Islam yaitu Muhammad Abduh, beliau mempunyai lingkungan yang 
tidak sesuai dengan yang ia harapkan, karena pada saat masyarakat sekitar lingkungannya merupakan masyarakat yang kental dengan kebudayaan para terdahulunya (Suwito, 2005: 89).

Pemikiran mereka tidak bisa diajak untuk kompromi dengan tujuan pengembangan tentang kehidupan yang lebih baik, baik dari segi kehidupan masyarakatnya, ekonomi dan lebih-lebih dalam bidang pendidikan, dari pentingnya pendidikan itulah Muhammad Abduh merencanakan ada perubahan yang konkrit terhadap pendidikan yang pada saat itu beliau mempunyai peran penting disebuah pendidikan perguruan tinggi yang memang pada saat itu perguruan tinggi al-Azhar merupakan perguruan tinggi yang mempunyai peran penting di negara tersebut, dengan hal itu Muhammad Abduh tidak menyianyiakan jabatan yang pada saat itu beliau emban, dengan secara perlahan beliau memasukkan kurikulum pendidikan yang pada saat itu filsafat dijadikan mata kuliah di perguruan tinggi al-Azhar, beliau berkeinginan dengan dimasukannya mata kuliah filsafat tersebut menjadikan mahasiswa berfikirnya lebih luas.

\section{Riwayat Hidup Muhammad Abduh}

Tempat tanggal dan lahir dari seorang Muhammad Abduh belum diketahui secara pasti, karena disebabkan orang tua dari Muhammad Abduh tempat tingalnya selalu berpindah-pindah dan yang pasti beliau lahir pada era pemerintahan Muhammad Ali (1805-1849) (Rusli, 2013: 99).

Pemerintahan pada saat itu yang dipimpin oleh Muhammad Ali bersifat semanya sendiri, maka dengan hal tersebut para pegawainya bersikap keras dalam melaksanakan kehendak dan perintahnya, rakyat merasa ditindas Atas sikap Muhammad Ali, maka dengan hal itu semua rakyat ada yang berpindahpindah termasuk didalamnya keluarga Muhammad Abduh.

Namun ada literatur juga yang mengatakan bahwa Muhammad Abduh lahir pada tahun 1848 M/ 1265 H disebuah Desa di Propinsi Gharbiyyah Mesir Hilir. Dengan nama seorang ayah Muhammad 'Abduh Ibn Hasan Khairullah, Muhammad Abduh lahir dari lingkungan keluarga petani yang hidup dengan penuh kesederhanaan, taat dan cinta ilmu pengatahuan, orang tua dari 
Muhammad Abduh berasal dari kota Mahallaj Nashshr, begitu juga kehidupan orang tua Muhammad Abduh sama seperti halnya diatas bahwa kehidupan orang tua Muhammad Abduh berpindah-pindah disebabkan kepemimpinan pada saat itu termasuki oleh bias-bias politik yang tidak baik (Nizar, 2013: 240).

Muhammad Abduh tidak hanya cukup kepada satu guru saja, beliau mempunyai guru yang bisa dibilang banyak, karena menurut beliau meskipun guru kalau tidak sesuai dengan alur pemikirannya maka Muhammad Abduh mencari guru yang lain dengan alasan ilmu yang diperoleh banyak dan pengalaman dari masing-masing guru tidak sama, diantara guru yang pernah beliau timba ilmunya adalah Syaikh Ahmad di Tantha, dari ulama' ini Muhammad Abduh mempelajari tentang ilmu agama, diantaranya beliau belajar membaca dan menulis al-Qur'an, setelah beliau fasih maka oleh orang tuanya menyerahkan kepada seorang guru untuk menghafal al-Qur'ān dan dua tahun kemudian beliau hafal al-Qur'ān,meskipun pada awalnya Muhammad Abduh merasa ragu dan agak kurang semangat, namun dengan dorongan dari paman-pamanya yaitu Syaikh Darwis Khadar, Abduh akhirnya dapat menyelesaikan pelajarannya di tahnta. tidak lama kemudia beliau melanjutkan ke Perguruan tinggi al-Azhar disana beliau belajar ilmu Mantihiq dan Balaghah dari Syaikh Hasan Al-Thawil Dan Syaikh Muhammad al-Basyuni selesai pada tahun 1877 (Nata, 2013: 307).

Setelah selesai belajar di Tantha, pada usia 17 tahun Muhammad Abduh seperti yang sudah disebutkan diatas bahwa Muhammad Abduh melanjutkan study ke al-Azhar Kairo, lima tahun kemudian ia berjumpa dengan Jamaluddin al-Afghani, Muhammad Abduh sangat tetarik dengan perkuliyahan yang disampaikan oleh Jamaluddin Al-Afghani dengan hal itu Muhammad Abduh menjadi murid yang paling setia. diantara mata kuliah yang paling beliau sukai adalah falsafat, sejarah, hukum dan pemikiran teologi rasional, pada tahun 1877 beliau lulus dengan gelar 'Alim (Nata, 2013: 100-101).

Di sisi lain dampak dari bermainnya politik Muhammad Abduh ini, beliau juga diasingkan ke Beirut dan kemudian ke Paris, karena dituduh terlibat dalam pemberontakan Urabi Pasya tahun 1882, Tapi dengan kejadian hal tersebut tidak membuat Muhammad Abduh jera terhadap politiknya, bahkan Beliau lebih 
semangat lagi berpolitik dan sasaranya jugapun bukan hanya negara pemerintah Mesir, tetapi kepada seluruh kaum muslimin sedunia, dengan cara antara Muhammad Abduh dengan Jamaluddin al-Afghani menerbitkan majalah dengan judul al-'Urwah al-Wusqâ.beliau menerbitkan majalah ini dengan tujuan membangkitkan semangat kaum muslimin untuk melawan kekuasaan kaum penjajah (Barat).

Tidak lama kemudian Muhammad Abduh bisa menghirup udara segar lagi di Mesir pada tahun 1888 M, Muhammad Abduh diperkenan kembali lagi ke Mesir. tetapi Muhammad Abduh sudah tidak lagi diberikan ruang untuk mengajar di alAzhar lagi dikarnakan takut mempengaruhi mahasiswanya, tapi oleh pemerintah Mesir Muhammad Abduh dikasih amanah lain yaitu sebagai hakim pada salah satu pengadilan di mesir, kemudian pada tahun 1894 beliau diangkat sebagai anggota Majlis Ala al-Azhar. Dalam jabatan tersebut Muhammad Abduh banyak memberikan sumbangsih perubahan dan perbaikan bagi Universitas al-Azhar. Pada perkembangan berikutnya beliau diangkat menjadi mufti besar mesir pada tahun 1899 M sampai beliau wafat yaitu tanggal 11 Juli 1905 di kairo (Suwito, 2005: 255-256).

\section{Modernisasi Pemikiran Pendidikan Islam}

Pengalaman di Beirut membuat Muhammad Abduh semakin yakin bahwa dengan ada perubahan dalam pendidikan bisa membuat perubahan yang sanagat signifikan dalam membangun sebuah bangsa yang lebih baik, ketika beliau pulang dari pengasingan maka beliau ingin aktif lagi di pendidikan, namun pemerintah berbeda, justru Muhammad Abduh dijadikan seorang hakim.Ketika beliau menjadi hakim maka semua keputusannya bertujuan mendidik rakyat. Demikian juga ketika ada dikursi perlemen (Majlis Syura), keputusannya pun bertujuan untuk mendidik rakyat, Muhammad Abduh bukanlah seorang revolusioner yang mengadakan pembaharuan yang singkat, namun beliau seorang pendidik yang membawa pembaharuan melalaui pendidikan yang memakan waktu yang panjang. 
Muhammad Abduh mempunyai semangat yang tinggi untuk memajukan dunia Islam, dengan jalan memperbaharui pendidikan yang sudah ada pada saat itu, sifat dari pembaharuan pendidikan Muhammad Abduh ini selain modern, juga di dalamnya terdapat pemikiran tentang politik, kebangsaan, sosial kemasyarakatan, teologi dan filsafat. Tidak hanya disitu corak pemikiran Muhammad Abduh ini juga sifatnya pada teologi rasional, filsafat dan sejarah. Dengan corak pemikiran yang berbeda-beda itu maka seorang Muhammad Abduh menemukan dan mengemukakan ide-ide ataupun gagasan baru dan hal itu disesuaikan dengan perkembangan zaman pada saat itu (Siswanto, 2009: 308).

Dalam gerakan pembaharuan pemikiran Islam abad 19 ada tiga pola pemikiran yang dijadikan panduan, Namun Penulis hanya mengambil satu pola, karena pola ini berkaitan langsung dengan pemikiran Muhammad Abduh dalam bidang pendidikian yaitu pola, Islamisme yaitu pemikiran yang condong terhadap keagamaan Islam, pola inilah yang mengatakan bahwa islamlah yang menjadi sumber dari kemajuan dan perkembangan pengatahuan modern, adapun sebab kemundurannya adalah karena umat Islam sendiri meninggalkan ajaran Islam, meskipun mereka melaksanakannya hanya sebagian saja. Maka dari sinilah tumbuh prinsip bahwa islam harus dijadikan dasar pendidikan Islam.

Tokoh dari pembaharu ini sebenarnya adalah Muhammad Abdul wahab dengan programnya kembali kepada al-Qur'ān dan hadis. Tetapi program ini terlaksana pada masa al-Afghani dan Muhammad Abduh, dalam hal ini Muhammad Abduh tidak terlalu fundamental seoperti halnya Muhammad Abdul Wahab, menurut Muhammad Abduh kembali kepada ajaran Islam tidak harus persis dengan ajaran tekstualnya karena islam itu sesuai dengan perkembangan zaman. Dalam dunia pendidikan Muhammad Abduh diwujudkan dalam upayanya untuk memasukkan materi umum di perguruan tinggi al-Azhar, tetapi gagal karena adanya tantangan ulama-ulama konservatisme yanag ada pada waktu (Ngatini, 2010: 96-97). Pendidikan yang dilakukan oleh Muhammad Abduh sifatnya lebih mengarah kepada menghilangkan dikotomi pendidikan, 
mengembangkan kelembagaan pendidikan, pengembalan kurikulum dan metode pengajaran (Ngatini, 2010: 308).

Ketika Muahammad Abduh berada dimesir pada saat itu juga berkembang dua model pendidikan, model pertama "Sekolah Moderen", baik sekolah itu dibangun oleh pemerintah mesir atau oleh pihak asing, sekolah ini tentunya tujuannya tidak lain adalah menekankan kepada kecerdasan intelektual saja, dan hal itu dampak dari pembaharuan pendidikan yang dilakukan oleh pemerinatahan Mohammad Ali, Pendidikan semacam ini output yang dihasilkan adalah generasi muda yang lebih cendrung kepada ilmu-ilmu barat. Maka dengan keadaan seperti itu Muhammad Abduh berfikir bahwa pendidikan model seperti halnya pendidikan modern akan dapat mengancam keberadaan agama dan moral masyarakat, Dengan alasan karena pemikiran-pemikiran orang barat akan secara perlahan mengoyahkan pemikiran orang-orang Islam pada saat itu. Adapun model pendidikan yang kedua yaitu model "Sekolah Agama", yang masih bercorak tradisional dan doktrinan, adapun alumni yang dihasilkan adalah adalah para ulama' dan para tokoh masyarakat yang tidak mau terhadap peruabahan dan masih mempertahankan tradisi. Dengan hal tersebut Muhammad Abduh mempunyai asumsi bahwa model sekolah yang kedua ini tidak dapat dipertahankan lagi, dengan alasannya islam akan tertinggal dengan pesatnya perkembangan zaman. Oleh karena itu, Muhammad Abduh bermaksud untuk menghilang dikotomi antara pendidikan yang modelnya ada dua seperti yang telah disebutkan di atas, baik secara kelembagaan dengan cara mensinergikan kedua model tersebut sehingga jurang pemisah antara keduanya dapat disatukan (Suharto, 2011: 277-288).

Di samping persoalan tentang dikotomi pendidikan Muhammad Abduh juga dihadapkan kepada pendidikan yang terkesan bersifat ortodoks dan tradisional. Hal ini karena masih mengentalnya pengaruh dan dipengaruhi pola pemikiran yang mengarah kepada sekterianisme aliran madzhab. Dengan persoalan tersebut dapat dipahami bahwa pendidikan merupakan tempat perubahan dan prosesi pengkaderan generasi (Tim Dosen Fakultas Tarbiyah UIN Maulana Malik Ibrahim Malang: 353). 
Yusuf Suyono dalam bukunya "Reformasi Teologi" yang mengutip Gibb, bahwa pembaharuan pendidikan Muhammad Abduh bisa diklasifikasikan menjadi empat hal:

a. Pemurnian Islam dari berbagai pengaruh ajaran dan pengamalan yang tidak benar (Bid'ah dan khufarat)

b. Pembaharuan pendidikan tinggi Islam

c. Perumusan kembali ajaran agama sejalan dengan pemikiran modern

d. Pembelaan Islam terhadap pengaruh Eropa dan serangan-serangan Kristen (Suyono, 2008: 42).

Modernisasi Pendidikan Islam tersebut kemudian perlu aktualisasikan mengingat perlunya pengembalian identitas pendidikan sebagai langkah dalam menghilangkan pengaruh aliran.

\section{Pengembangan Kurikulum}

Sebelum kita memahami kurikulum pendidikan menurut Muhammad Abduh lebih efektifnya kita memahami kurikulum pendidikan secara umum terlebih dahulu, Kurikulum (manhaj curriculum) adalah separangkat perancanaan dan media untuk mengantar lembaga pendidikan dalam mewujudkan tujuan pendidikan yang diinginkan (Mujib: 206: 122).

Dalam pengertian yang sempit, kurikulum merupakan seperangkat rencana dan pengaturan tentang isi dan bahan pelajaran serta cara yang digunakan sebagai pedoman penyelenggaraan kegiatan belajar mengajar di sekolah (Muhaimin, 2003: 182). Kurikulum sangat berpengaruh dalam menunjang keberhasilan prosespembelajaran, mengingat perannya yang begitu luas dalam dunia pendidikan.

Melihat pemahaman kurikulum pendidikan di atas setidaknya kita sudah dapat memahami bahwa kurikulum pendidikan itu merupakan salah satu unsur agar tujuan dari sebuah pendidikan berhasil, begitu juga Muhammad Abduh dalam hal pengembangan kurikulum tidak hanya mencangkup satu kelembagaan satu saja, tetapi mulai dari pendidikan sekolah dasar, sekolah menengah, 
kejuruan dan Perguruan tinggi al-Azhar. Kita dapat merinci pengembangan kurikulum menurut Muhammad Abduh sebagai berikut:

a. Pengembangan Kurikulum pada Perguruan tinggi al-Azhar

Secara Perguruan tinggi Kurikulum ini fokus kepada peguruan tinggi alAzhar, yang memang pada saat itu Muhammad abduh dengan semangat yang tinggi ingin ada perubahan dalam perguruan tinggi al-Azhar, Kurikulum perguruan tinggi al-Azhar disesuaikan dengan kebutuhan masyarakat pada saat itu. Dalam hal ini, Muhammad Abduh memasukkan ilmu filsafat, logika dan ilmu pengatahuan modern ke dalam kurikulum al-Azhar yang pada awalnya mata kuliah ini tidak dicantumkan oleh pihak pihak perguruan tinggi al-Azhar. Dengan tujuan output-nya menjadi ulama' yang modern (Nizar, 2011: 249)

Akan tetapi dalam perjalanan pembaharuan Muhammad Abduh tersebut tidak semudah membalikkan tangan, namun masih ada rintangan seperti halnya, beliau dapat tantangan dari para ulama' yang masih berpegangan teguh pada tradisi lama.Tantangan tersebut semakin keras ketika Khadevi Abbas terpengaruh dan akhirnya tidak merestui usaha-usaha pembaharuan Muhammad Abduh (Rusli, 2013: 108-109).

Perlu kita ketahui juga bahwa rintangan yang dihadapi oleh Muhammad Abduh dalam memperbaiki kurikulum tersebut beliau dapat tantangan dari ulama' seperti yang sudah disampaikan di atas, Muhammad Abduh disangka akan menghidupkan kembali pemikiran-pemikiran Mu'tazilah oleh para ulama' pada saat itu, seperti Syekh Alaisy, Muhammad Abduh ruang lingkupnya hanya terbatas, karena berhadapan dengan ulama' konservatif (Siswanto, 2013: 130). Alasan lain ulama' yang tidak sepakat dengan pembaharuan Muhammad Abduh ini diantaranya karena para ulama itu belum dapat melihat faidah perubahan-perubahan yang dianjurkannya (Asrohah, 2001: 135).

Muhammad Abduh dalam kurikulum al-Azhar ini selain mempersatukan dikotomi-dikotomi, Abduh juga memperkenalkan ilmu dan sains modern, yang pada saat itu hanya memuat ilmu-ilmu keislaman saja. Abduh menjadikan alAzhar ini sebagai laboratium pemikirannya yang mengajarkan ilmu 
pengatahuan modern, disamping juga mempertahankan ilmu-ilmu islam klasik. Selain falsafah, abduh juga berhasil memasukkan matematika, aljabar, ilmu ukur dan ilmu bumi kedalam kurikulum al-Azhar (Assegaf, 2013: 185186).

b. Pengembangan Kurikulum Sekolah Dasar

Menurut Muhammad abduh dasar-dasar pembentukan jiwa agama atau karakter yang baik sehendaknya dilaksanakan sejak masa kanak-kanak.oleh karena itu mata pelajaran agama agar dijadikan pelajaran wajib pada semua mata pelajaran, beliau mengacu kepada anggapan bahwa agama islam merupakan dasar pembentukan jiwa dan pribadi Islam, dengan hal itu khususnya kepada masyarakat mesir ketika sudah tertanam jiwa dan pribadi muslim, maka terwujudlah kebersamaan dan nasionalisme antara yang satu dengan yang lainnya, dengan tujuan agar tercipta kehidupan yang lebih baik dan sekaligus meraih kemenangan (Nata, 2013: 310-311).

Dalam kurikulum sekolah dasar ini Muhammad Abduh memberikan ruang lingkup yang meliputi membaca, menulis, berhitung sampai pada tingkat tertentu dan pelajaran yang berkenaan dengan agama dan sejarah (Tim Dosen Fakultas Tarbiyah UIN Maulana Malik Ibrahim Malang, tt: 360).

c. Pengembangan Kurikulum Tingkat Menengah

Dalam hal ini meliputi mantiq atau logika, dan dasar-dasar logika, aqidah, fiqih, akhlaq dan sejarah islam secara komprehensif. Sama halnya apa yang disampaikan Abuddin nata dalam bukunya "Pemikiran Pendidikan Islam dan Barat", Bahwa pengembangan kurikulum tingkat menengah memasukkan mata pelajaran yang sebelumnya tidak dimasukkan di mata pelajaran pada tingkat menengah, seperti halnya falsafah dan mantiq, selain itu, dimasukkan pula pelajaran tentang sejarah dan peradaban Islam dengan tujuan agar umat Islam mengetahui berbagai perkembangan dan kemajuan yang pernah tercapai pada masa silam, dan hal itu sebagai pemicu untuk membangun semangat baru umat Islam.

Dengan pengembangan kurikulum pada masing-masing lembaga tersebut merupakan gambaran secara umum dari kurikulum pelajaran agama 
yang diterapkan pada setiap tingkat, tapi dalam hal ini Muhammad abduh tidak memasukkan ilmu-ilmu barat kedalam kurikulum yang direncanakan, maka dengan demikian dalam pendidikan formal Muhammad abduh menekankan kepada mata pelajaran yang sifatnya agama seperti halnya, fikih, sejarah Islam, akhlak dan bahasa (Nizar, 2011: 250).

\section{Pengembangan Metode Pengajaran}

Metode pembelajaran merupakan salah satu komponen pembelajaran yang dijadikan identitas dalam kegiatan pembelajaran, baik di tingkat kelas hingga lembaga pendidikan. Begitu pula dalam pemikiran Muhammad Abduh yang memiliki ciri khas tersendiri dalam menyampaikan materi pembelajaran, hal tersebut dilakukan untuk mencapai efektifitas dalam mencapai tujuan pendidikan yang dirancangnya.

Oleh karena itu, selain kurikulum dan materinya, metode juga perlu diperhatikan, secara umum metode dalam pembelajaran baik disekolah atau di madrasah, meliputi: 1) pendekatan keimanan, 2) pendekatan pengalaman, 3) pendekatan pembiasaan, 4) pendekatan rasional, 5) pendekatan emosional, 6) pendekatan funsional, 7) pendekatan keteladanan (Maksum, 2011:38-39).

Menurut Muhammad abduh bahwa metode pengajaran yang selama ini hanya mengandalkan hafalan perlu dilengkapi metode yang rasional dan pemahaman (insigh), Maka dengan yang sedemikian disamping murid menghafal mata pelajaran, dia juga bisa memahami pelajaran secara kritis, objektif dan komperhensif, Dalam bukunya Sofan Amri "Proses pembelajaran", Dalam proses belajar yang perlu diperhatikan diantaranya ialah, Belajar tidak hanya sekedar menghafal. Peserta didik harus mengkrontruksi pengatahuan di jiwa mereka (Amri dkk, 2010: 22). Muhammad Abduh juga mengusung pikiran yang sama dengan para pendahulunya, menurutunya akal intelektual adalah dasar dalam Islam, jadi dalam metode pembelajaran abduh sama-sama menggunakan hafalan dan diskusi (Muhammad, 2011: 34).

Muhammad Abduh juga menawarkan metode mengajar dengan menghidupkan kembali metode diskusi (munadzarah), dalam memahami ilmu 
pengetahuan dan menjauhkan diri dari metode taklid buta terhadap para ulama', di sisi lain Muhammad Abduh juga menerapkan kebebasan mengembangka ilmiah dikalangan mahasiswa di perguruan tinggi al-Azhar.Muhammad Abduh juga menghidupkan kembali pelajaran bahasa Arab yang selama ini hanya merupakan ilmu yang tidak berkembang menjadikan ilmu yang berkembang yang dapat dipergunakan untuk menterjemahkah teks-teks pengetahuan modern ke dalam bahasa Arab (Ramayulis \& Nizar, 2013: 294).

Muhammad Abduh juga mengkritik dengan tajam yang memang pada saat itu metode hafalan umum diaplikasikan disetiap lembaga pendidikan di mesir, terutama Pendidikan Agama. Muhammad Abduh dalam tulisannya tidak menjelaskan secara mendetail tentang metode apa yang diterapkan, tetapi melihat metode yang sering dilakukan waktu beliau mengajar di perguruan tinggi al-Azhar tampaknya ia menerapkan metode diskusi untuk memberikan pengertian yang mendalam kepada peserta didiknya. ia juga menyampaikan kepada pendidik yang lain untuk tidak mengajar peserta didik dengan metode menghafal, karena metode yang demikian akan merusak daya nalar, Muhammad abduh memberikan alasan seperti itu, karena berangkat dari pengalaman pribadinya waktu beliau belajar di sekolah formasi di Masjid Ahmadi di Thanta (Nizar, 2011: 250).

\section{Penutup}

Sejarah Hidup Muhammad Abduh Tempat tanggal dan lahir dari seorang Muhammad Abduh belum diketahui secara pasti, karena disebabkan orang tua dari Muhammad Abduh tempat tingalnya selalu berpindah-pindah dan yang pasti beliau lahir pada era pemerintahan Muhammad Ali (1805-1849).

Modernisasinya Muhammad Abduh diawali dengan semangat yang tinggi untuk memajukan dunia Islam, dengan jalan memperbaharui pendidikan yang sudah ada pada saat itu, sifat dari pembaharuan pendidikan Muhammad Abduh ini selain modern, juga didalamnya terdapat pemikiran tentang politik, kebangsaan, sosial kemasyarakatan, teologi dan filsafat. Tidak hanya disitu corak pemikiran Muhammad abduh ini juga sifatnya pada teologi rasional, filsafat dan 
sejarah. Modernisasi pemikiran pendidikan Islam Muhammad Abduh adalah Pengembangan Kurikulum, Metode pengajaran juga tidak lepas dari pembaharuan seorang Muhammad Abduh, menurut beliau metode yang selama ini dipakai oleh lembaga pendidikan, terutama pendidikan yang ada di mesir hanya fokus terhadap hafalan dan hal itu menurut beliau tidak baik terhadap perkembangan intelektual seorang peserta didik, dengan hal itu Muhammad abduh mengembangkan metode mengajar dengan berdiskusi dengan tujuan agar pemahaman peserta didik tambah luas dengan tidak melanggar aturan syariat Islam. 


\section{DAFTAR PUSTAKA}

Amri, Sofan dkk. 2010. Proses Pembelajaran, Jakarta: PT. Prestasi Pustaka.

Arif, Mukkhrizal, dkk. 2014. Pendidikan Posmmodernisme. Yogyakarta: ArRuzz Media.

Asrohah, Hanun. 2001. Sejarah Pendidikan Islam. Jakarta: PT. Logos Wacana Ilmu.

Assegaf, Abd Rachman. 2013. Aliran Pemikiran Pendidikan Islam: Hadharah Keilmuan Tokoh Klasik Sampai Modern. Jakarta: PT Raja Grafindo Persada.

Depertemen Agama RI, 2009, al-Qurán dan Terjemahan, Jakarta: Tp.

Erwin Mahrus, Syamsul Kurniawan. 2011. Jejak Pemikiran Tokoh Pendidikan Islami, Jogjakarta: Ar-Ruzz Media.

Lestari, Ngatini. 2010. Pendidikan Is/am Kontekstual. Yogyakarta: Pustaka Belajar.

Maksum, Ali. 2011. Pluralisme dan Multikulturalisme Paradigma Baru Pendidikan Agama Islam di Indonesia. Yogyakarta: Aditya Media Publishing.

Muhaimin. 2003. Wacana Pengembangan Pendidikan Islam. Yogyakarta: Pustaka Belajar.

Muhammad, Husein. 2011. Mengaji Pluralisme Kepada Mahaguru Pencerahan, Bandung: Mizan Media Utama.

Mujib, Abdul. 2006. IImu Pendidikan Islam. Jakarta: Prenada Media Group.

Nasution, Harun. 2001. Pembaharuan dalam Islam Sejarah Pemikiran dan Gerakan. Jakarta: PT Bulan Bintang.

Nata, Abudin. 2013. Pemikiran pendidikan Islam dan Barat. Jakarta: PT. Raja Grafindo Persada.

Nizar, Samsul. 2011. Sejarah Pendidikan Islam Menelusuri Jejak Sejarah Pendidikan Era Rasulullah Sampai Indonesia. Jakarta: Prenda Media Group. 
Qardhawi, Yusuf. 1999. Syaikh Muhammad al-Ghazali yang Saya Kenal:Setengah Abad Perjalanan Pemikiran dan Gerakan Islam, Terj. Surya Darma Jakarta: Robbani Press.

Ramayulis, Samsul Nizar. 2013. Filsafat Pendidikan Islam. Jakarta: Kalam Mulia.

Rusli, Ris'an. 2013. Pembaharuan Pemikiran Modren Dalam Islam. Jakarta: PT. Raja Grafindo Persada.

Siswanto. 2009. Pendidikan Islam dalam Perseepektif Filosofis. Pamekasan: STAIN Pamekasan Press. . 2013. Dinamika Pendidikan Islam. Surabaya: Pena Salsabila.

Suharto, Toto. 2011. Filsafat Pendidikann Islam. Jogjakarta: Ar-Ruzz Media.

Suwito, 2005. Sejarah Sosial pendidikan Islam. Jakarta: Prenada Media.

Suyono, Yusuf. 2008. Reformasi Teologi. Semarang: RaSAIL Media Group.

Tim Dosen Fakultas Tarbiyah UIN Maulana Malik Ibrahim Malang. (tt) Pendidikan Islam dari Pradigma Klasik Hingga Kontemporer Malang: Uin-Malang Press. 